\title{
Effects of potential detoxifying agents on growth performance and deoxynivalenol (DON) urinary balance characteristics of nursery pigs fed DON-contaminated wheat ${ }^{1,2}$
}

\author{
H.L. Frobose,* E. W. Stephenson,* M.D. Tokach,* \\ J.M. DeRouchey, * J. C. Woodworth, * S.S. Dritz†, and R.D. Goodband*3 \\ *Department of Animal Sciences and Industry, College of Agriculture, \\ Kansas State University, Manhattan 66506-0210; and $\dagger$ Department of Diagnostic \\ Medicine/Pathobiology, College of Veterinary Medicine, Kansas State University, Manhattan 66506-0210
}

\begin{abstract}
Two experiments were conducted to evaluate potential detoxifying agents on growth of nursery pigs fed deoxynivalenol (DON)-contaminated diets. Naturally DON-contaminated wheat $(6 \mathrm{mg} / \mathrm{kg})$ was used to achieve desired DON levels. In a 21-d study, 238 pigs $(13.4 \pm 1.8 \mathrm{~kg} \mathrm{BW})$ were used in a completely randomized design with a $2 \times 2+1$ factorial arrangement. Diets were: 1) Positive control $(\mathrm{PC} ;<0.5 \mathrm{mg} / \mathrm{kg} \mathrm{DON}), 2) \mathrm{PC}+1.0 \%$ Product $\mathrm{V}$ (Nutriquest LLC, Mason City, IA), 3) Negative control (NC; $4.0 \mathrm{mg} / \mathrm{kg} \mathrm{DON}), 4) \mathrm{NC}+1.0 \%$ Product V, and 5) $\mathrm{NC}+1.0 \%$ sodium metabisulfite (SMB; Samirian Chemicals, Campbell, CA). There were 6 or 7 replicate pens/treatment and $7 \mathrm{pigs} / \mathrm{pen}$. Analyzed DON was decreased by $92 \%$ when pelleted with SMB, but otherwise matched formulated levels. Overall, a DON $\times$ Product $\mathrm{V}$ interaction was observed for ADG $(P<0.05)$ with a tendency for an interaction for ADFI $(P<0.10)$. As anticipated, DON reduced $(P<0.001)$
\end{abstract} $\mathrm{ADG}$ and ADFI, but the interaction was driven by even poorer growth when Product $\mathrm{V}$ was added to NC diets. Pigs fed NC diets had 10\% poorer G:F $(P<0.001)$ than PC-fed pigs. Reductions in ADG due to DON were most distinct $(50 \%)$ during the initial period. Adding SMB to NC diets improved $(P<0.01)$ ADG,
ADFI, and G:F, and improved $(P<0.02)$ ADG and G:F compared to the PC diet. A urinary balance study was conducted using diets 3 to 5 from Exp. 1 to evaluate Product V and SMB on DON urinary metabolism. A $10 \mathrm{~d}$ adaptation was followed by a $7 \mathrm{~d}$ collection using 24 barrows in a randomized complete block design. Pigs fed NC + SMB diet had greater urinary DON output $(P<0.05)$ than pigs fed $\mathrm{NC}+$ Product $\mathrm{V}$, with NC pigs intermediate. Daily DON excretion was lowest $(P<0.05)$ in the NC + SMB pigs. However, degradation of DON-sulfonate back to the parent DON molecule was observed as pigs fed $\mathrm{NC}+\mathrm{SMB}$ excreted more DON than they consumed (164\% of daily DON intake), greater $(P<0.001)$ than pigs fed the NC $(59 \%)$ or NC + Product V (48\%). Overall, Product V did not alleviate DON effects on growth nor did it reduce DON absorption and excretion. However, hydrothermally processing DON-contaminated diets with $1.0 \%$ SMB restored ADFI and improved G:F. Even so, the urinary balance experiment revealed that some of the converted DON-sulfonate can degrade back to DON under physiological conditions. While further research is needed to discern the stability of the DON-sulfonate, SMB appears promising to restore performance in pelleted DON-contaminated diets.

Key words: adsorbents, deoxynivalenol, mycotoxins, nursery pigs, sodium metabisulfite

\section{(C) 2017 American Society of Animal Science. All rights reserved.}

\footnotetext{
${ }^{1}$ Contribution No. 16-340-J from the Kansas Agric. Exp. Sta., Manhattan 66506-0210.

${ }^{2}$ Appreciation is expressed to Nutriquest LLC (Mason City, IA) for supplying the deoxynivalenol-contaminated wheat and partial financial support of the study.

${ }^{3}$ Corresponding author: goodband@ksu.edu

Received May 23, 2016.

Accepted November 9, 2016.
}

J. Anim. Sci. 2017.95:327-337 doi:10.2527/jas2016.0664

\section{INTRODUCTION}

Cereal grains are the principal component in swine diets since the efficiency of cost per calorie provided surpasses other ingredients. Nevertheless, fungal infection often occurs, and these fungi leave behind secondary metabolites, known as mycotoxins, 
which have adverse effects on livestock if ingested in sufficient quantities. The bioavailability of some mycotoxins (e.g., aflatoxins or zearalenone) can be reduced by including adsorbent compounds, which reduce mycotoxin uptake and distribution to the blood and target organs (CAST, 2003; Burel et al., 2009).

According to a 3-yr global survey (Rodrigues and Naehrer, 2012), the most prevalent (65\% of finished feed) mycotoxin in North American feedstuffs is deoxynivalenol (DON), known for its feed intake suppression (Friend et al., 1984) and immunomodulatory effects (Pestka et al., 2004) in pigs when present in diets at over $1 \mathrm{mg} / \mathrm{kg}$. Despite DON's prevalence and known effects, adsorbent compounds have proven largely ineffective against DON in both in vitro models and in vivo growth studies (Danicke, 2002). Although no DONdetoxifying agents have efficacy claims approved by the U.S. Food and Drug Administration, some products are reported to be of benefit. One such compound is Product V (Nutriquest LLC, Mason City, IA), a proprietary blend of adsorbent clays and preservatives. Since nursery pigs are known for their sensitivity to antinutritional factors such as mycotoxins, the objective was to test the growth performance of nursery pigs fed a naturally DONcontaminated diet in the presence or absence of Product $\mathrm{V}$, and to record DON absorption and excretion using urinary concentration of DON metabolites. Sodium metabisulfite (SMB; $\left.\mathrm{Na}_{2} \mathrm{~S}_{2} \mathrm{O}_{5}\right)$, a known biotransforming agent of DON which, when hydrothermally processed with DON, forms a nontoxic DON-sulfonate adduct (Beyer et al., 2010), and sulfur dioxide was also incorporated into naturally contaminated diets to further evaluate SMB's potential for use in DON-contaminated diets.

\section{MATERIALS AND METHODS}

The Kansas State University Institutional Animal Care and Use Committee approved the protocol used in this experiment. The nursery and metabolism barns used were both totally enclosed, environmentally controlled, and mechanically ventilated. Sources of naturally DON-contaminated hard red winter (HRW) wheat and uncontaminated HRW wheat were acquired and an initial 17-component mycotoxin screen was performed at North Dakota State University Veterinary Diagnostic Laboratory (NDSU) using a combination of mass spectrometry, ELISA, and HPLC methods. Based on the analyzed DON concentration, an equal amount of high-DON $(6.03 \mathrm{mg} / \mathrm{kg})$ or low-DON $(0.05 \mathrm{mg} / \mathrm{kg}$ DON) wheat was incorporated into experimental diets to achieve desired DON concentrations. Wheat sources were hammer mill ground to approximately $600 \mu$, and each source was homogenously blended to minimize any variation in DON concentration between diets.
Diets were formulated to meet or exceed NRC (2012) requirements and to be identical in nutrient composition apart from DON concentration and the inclusion of detoxifying agents (Table 1). Diets for the growth performance and urinary balance experiment were manufactured simultaneously at the Kansas State University O.H. Kruse Feed Mill. The 5 experimental diets were: 1) Positive control (PC; $<0.5 \mathrm{mg} / \mathrm{kg} \mathrm{DON}) ; 2) \mathrm{PC}+$ $1.0 \%$ Product V (a proprietary blend of adsorbent clays and preservatives); 3) Negative control (NC; $4.0 \mathrm{mg} /$ $\mathrm{kg} \mathrm{DON})$; 4) $\mathrm{NC}+1.0 \%$ Product V; and 5) $\mathrm{NC}+1.0 \%$ $\mathrm{SMB}\left(\mathrm{Na}_{2} \mathrm{~S}_{2} \mathrm{O}_{5}\right.$; Samirian Chemicals, Campbell, CA). Two large batches using the low- or high-DON wheat were initially mixed to ensure consistency in DON levels. Each individual diet was then manufactured by subdividing the large batches and incorporating the appropriate detoxifying agent or sand at $1.0 \%$ of the final diet.

After mixing complete diets for $2 \mathrm{~min}$ in a double ribbon mixer, diets were pelleted (CPM Master Model $1000 \mathrm{HD}$; CPM, Crawfordsville, IN) at a production rate of $454 \mathrm{~kg} / \mathrm{h}$ to maintain a minimum conditioner retention time and temperature of $45 \mathrm{~s}$ and $82^{\circ} \mathrm{C}$, respectively. Diets were manufactured in numeric order to minimize carryover, with a flush between each diet. Feed mill worker safety was also accounted for since SMB liberates sulfur dioxide under hydrothermal conditions such as in the pelleting process. Although SMB is "generally recognized as safe" by the U. S. Food and Drug Administration, the production of sulfur dioxide by SMB is irritating to the respiratory tract epithelium, causes eye irritation, and can cause severe reactions in asthmatics (Nair and Elmore, 2003). Accordingly, all personnel involved were required to wear respirators and safety goggles during the pelleting process. Samples of each diet were collected both pre- and post-pelleting. Diet samples were stored, frozen, and shipped along with basal ingredient samples to LABOCEA (Ploufragan, France) for a mycotoxin profile analysis and to Ward Laboratories (Kearney, $\mathrm{NE)}$ for nutrient chemical analysis.

\section{Growth Experiment}

A total of 238 barrows and gilts (PIC $327 \times 1,050$; initially $13.4 \pm 2.5 \mathrm{~kg}$ and $40 \mathrm{~d}$ of age) were used in a 21-d growth study with 7 replicate pens per treatment and 7 pigs per pen; however, based on limited pen availability, 1 treatment (PC) had 6 replicate pens. Pigs were allotted to pens by initial BW at weaning, and when pigs reached approximately $13 \mathrm{~kg}$, they were reweighed and pen average pig BW was balanced across 1 of 5 treatments in a completely randomized design with a $2 \times 2+1$ factorial arrangement. Deoxynivalenol and Product $\mathrm{V}$ inclusion served 
Table 1. Composition of experimental diets (as-fed basis)

\begin{tabular}{|c|c|c|c|c|c|}
\hline Item & $\begin{array}{l}\text { Positive control } \\
\text { (PC) }\end{array}$ & $\begin{array}{c}\mathrm{PC}+1.0 \% \text { Product } \\
\mathrm{V}^{1} \\
\end{array}$ & $\begin{array}{c}\text { Negative control } \\
\text { (NC) }\end{array}$ & $\begin{array}{l}\mathrm{NC}+1.0 \% \\
\text { Product } \mathrm{V}\end{array}$ & $\begin{array}{c}\mathrm{NC}+1.0 \% \\
\mathrm{SMB}^{2}\end{array}$ \\
\hline Uncontaminated hard red winter (HRW) wheat & 67.00 & 67.00 & - & - & - \\
\hline Deoxynivalenol-contaminated HRW wheat, $6 \mathrm{mg} / \mathrm{kg}^{3}$ & - & - & 67.00 & 67.00 & 67.00 \\
\hline Soybean meal, $46.5 \% \mathrm{CP}$ & 24.16 & 24.16 & 24.16 & 24.16 & 24.16 \\
\hline Corn & 4.23 & 4.23 & 4.23 & 4.23 & 4.23 \\
\hline Limestone & 1.40 & 1.40 & 1.40 & 1.40 & 1.40 \\
\hline Monocalcium phosphate, $21 \% \mathrm{P}$ & 0.60 & 0.60 & 0.60 & 0.60 & 0.60 \\
\hline Salt & 0.35 & 0.35 & 0.35 & 0.35 & 0.35 \\
\hline L-Lysine- $\mathrm{HCl}$ & 0.50 & 0.50 & 0.50 & 0.50 & 0.50 \\
\hline DL-Methionine & 0.15 & 0.15 & 0.15 & 0.15 & 0.15 \\
\hline L-Threonine & 0.20 & 0.20 & 0.20 & 0.20 & 0.20 \\
\hline Vitamin premix ${ }^{4}$ & 0.25 & 0.25 & 0.25 & 0.25 & 0.25 \\
\hline Trace mineral premix ${ }^{5}$ & 0.15 & 0.15 & 0.15 & 0.15 & 0.15 \\
\hline Phytase $^{6}$ & 0.02 & 0.02 & 0.02 & 0.02 & 0.02 \\
\hline Product V & - & 1.00 & - & 1.00 & - \\
\hline Sodium metabisulfite & - & - & - & - & 1.00 \\
\hline Sand & 1.00 & - & 1.00 & - & - \\
\hline Total & 100.00 & 100.00 & 100.00 & 100.00 & 100.00 \\
\hline \multicolumn{6}{|l|}{ Calculated analysis } \\
\hline \multicolumn{6}{|l|}{$\mathrm{SID}^{7}$ amino acids, $\%$} \\
\hline Lys & 1.28 & 1.28 & 1.28 & 1.28 & 1.28 \\
\hline Ile:Lys & 59 & 59 & 59 & 59 & 59 \\
\hline Leu:Lys & 103 & 103 & 103 & 103 & 103 \\
\hline Met:Lys & 33.4 & 33.4 & 33.4 & 33.4 & 33.4 \\
\hline Met \& Cys:Lys & 57.6 & 57.6 & 57.6 & 57.6 & 57.6 \\
\hline Thr:Lys & 62.7 & 62.7 & 62.7 & 62.7 & 62.7 \\
\hline Trp:Lys & 18.4 & 18.4 & 18.4 & 18.4 & 18.4 \\
\hline Val:Lys & 63.9 & 63.9 & 63.9 & 63.9 & 63.9 \\
\hline Total Lys, \% & 1.41 & 1.41 & 1.41 & 1.41 & 1.41 \\
\hline $\mathrm{ME}, \mathrm{kcal} / \mathrm{kg}$ & 3131 & 3131 & 3131 & 3131 & 3131 \\
\hline SID Lys:ME, g/Mcal & 4.09 & 4.09 & 4.09 & 4.09 & 4.09 \\
\hline $\mathrm{CP}, \%$ & 20.8 & 20.8 & 20.8 & 20.8 & 20.8 \\
\hline $\mathrm{Ca}, \%$ & 0.72 & 0.72 & 0.72 & 0.72 & 0.72 \\
\hline $\mathrm{P}, \%$ & 0.61 & 0.61 & 0.61 & 0.61 & 0.61 \\
\hline Available P, \% & 0.42 & 0.42 & 0.42 & 0.42 & 0.42 \\
\hline
\end{tabular}

${ }^{1}$ A proprietary combination of adsorbent clays and preservatives (Nutriquest LLC, Mason City, IA).

${ }^{2}$ Sodium metabisulfite $\left(\mathrm{Na}_{2} \mathrm{~S}_{2} \mathrm{O}_{5}\right.$; Samirian Chemicals, Campbell, CA).

${ }^{3}$ Basal ingredient sample sent to the North Dakota State University Veterinary Diagnostic Laboratory (Fargo, ND) for a full 17-component toxin screen. Samples were analyzed using a variety of mass spectrometry, ELISA, and HPLC methods with a practical quantitation limit of $0.5 \mathrm{mg} / \mathrm{kg}$.

${ }^{4}$ Provided per kilogram of premix: 4,409,200 IU vitamin A; 551,150 IU vitamin $\mathrm{D}_{3}$; 17,637 IU vitamin E; 1,764 mg vitamin K; 3,307 mg riboflavin; $11,023 \mathrm{mg}$ pantothenic acid; $19,841 \mathrm{mg}$ niacin; and $15.4 \mathrm{mg}$ vitamin $\mathrm{B}_{12}$.

${ }^{5}$ Provided per kilogram of premix: $22.0 \mathrm{~g}$ Mn from manganese oxide; $73.4 \mathrm{~g} \mathrm{Fe}$ from iron sulfate; $73.4 \mathrm{~g} \mathrm{Zn}$ from zinc sulfate; $11.0 \mathrm{~g}$ Cu from copper sulfate; $198 \mathrm{mg}$ I from calcium iodate; and $198 \mathrm{mg}$ Se from sodium selenite.

${ }^{6}$ HiPhos 2700 (DSM Nutritional Products LLC, Parsippany, NJ) contains 2,708,400 phytase units/kg premix.

${ }^{7}$ Standardized ileal digestible.

as main effects with an additional treatment including SMB. Each pen $(1.22 \times 1.52 \mathrm{~m})$ contained a 4-hole, dry self-feeder and a nipple waterer to provide ad libitum access to feed and water. Pigs were examined daily and feeders were adjusted to maintain approximately $50 \%$ pan coverage. Average daily gain, ADFI, and $\mathrm{G}: \mathrm{F}$ were determined by weighing pigs and measuring feed disappearance on $\mathrm{d} 7,14$, and 21 .

\section{Urinary Balance Experiment}

A balance study was also conducted involving pigs individually housed in stainless-steel metabolism cages $(1.5 \times 0.6 \mathrm{~m})$. Each cage was equipped with a feeder and a nipple drinker for ad libitum access to water. To determine the effects of Product V and SMB on DON urinary excretion and metabolism, only the $3 \mathrm{NC}$ diets from the growth experiment were included. A total of 24 barrows 
were used over 2 replicate groups (12 pigs per group), with 4 pigs per dietary treatment in each group. Pigs were allotted to treatments in a randomized complete block design based on initial BW and location within the experimental room. Pigs were adapted to the diets and to an amount of feed consumed completely by all pigs ( 1.4 and $1.6 \mathrm{~kg}$ for groups 1 and 2, respectively) and to the metabolism cages during a 10-d adaption period. A 7-d collection period followed where daily feed intake and urinary output were recorded quantitatively. The mean initial BW at the start of the collection period was $42.6 \pm 1.7 \mathrm{~kg}$ and $51.8 \pm 3.5 \mathrm{~kg}$ for groups 1 and 2, respectively. Feed allocation was divided into 2 equal amounts and given twice daily at 0700 and $1500 \mathrm{~h}$. Due to the low recovery of DON and its primary metabolite de-epoxy-DON (DOM1 ) in feces ( 0.1 to $1.7 \%$ of DON intake) in similar studies (Danicke et al., 2007; Danicke et al., 2012), fecal DON and fecal DOM-1 were not analyzed in the present experiment. The separation of feces from urine was achieved by using differently sized screens located beneath the slatted floor of the cage and connected to a funnel and urine collection bottle. Each pig's total daily urine output was frozen and then thawed and homogenously mixed at the end of the collection period. A representative aliquot sample was collected and then frozen before being sent for a full mycotoxin screen at LABOCEA (Ploufragan, France) using liquid chromatography-tandem mass spectrometry with a practical quantitation limit of $0.01 \mathrm{mg} / \mathrm{kg}$.

\section{DON-Sulfonate Quantification}

The method used for DON-sulfonate analysis was described in Beyer et al. (2010). The primary objective of DON-sulfonate analysis was to confirm that the decreased analyzed DON in the pelleted NC + SMB diet was due to DON structural modification to form DONsulfonate, as demonstrated in prior research (Young et al., 1986; Paulick et al., 2015). An automated electrospray ionization-tandem mass spectrometry (ESI-MS/ MS) approach was used, and data acquisition and analysis were performed as in Beyer et al. (2010).

Unfractionated DON-sulfonate extracts were introduced by continuous infusion into the ESI source on a triple quadrupole MS/MS (4000QTrap; Applied Biosystems, Foster City, CA). An aliquot of $75 \mu \mathrm{L}$ of extract in methanol/water (3/1 vol/vol) was introduced using an autosampler (LC Mini PAL; CTC Analytics AG, Zwingen, Switzerland) fitted with the required injection loop for the acquisition time and presented to the ESI needle at $30 \mu \mathrm{L} / \mathrm{min}$.

A negative neutral loss scan of 80.9 was used to detect the DON-sulfonate molecular ion $377[\mathrm{M}-\mathrm{H}]^{-}$. The ESI-MS/MS parameters used were: DP -80, EP -10, CE-36, CXP -15, electrospray capillary voltage
-4500 , collision gas pressure 2 (arbitrary units), interface heater on, source temperature (heated nebulizer) $300^{\circ} \mathrm{C}$, curtain gas 20 , and both ion source gases 45 (arbitrary units). Seventy-five continuum scans were averaged in multiple channel analyzer mode (MCA).

The background of each spectrum was subtracted, the data were smoothed, and peak areas were integrated using Applied Biosystems Analyst software. For both replicate groups of the urinary balance experiment, samples of each diet $(n=3)$ were analyzed in triplicate. Peak areas of DON-sulfonate of $\mathrm{NC}+\mathrm{SMB}$ diet were compared to the peak areas of DON-sulfonate in $\mathrm{NC}$ diet and presented as a ratio.

\section{Statistical Analysis}

Data collected from both experiments were analyzed using analysis of variance in the MIXED procedure of SAS, version 9.1 (SAS Inst. Inc., Cary, NC). The growth experiment was a completely randomized design and treatment effects were assessed within each experimental period using pen as the experimental unit. The fixed factors in the model were DON level and the presence or absence of Product V. The preplanned contrasts in the growth experiment evaluated: 1) interactions between DON and Product V, 2) DON vs. noncontaminated, and 3) the absence or presence of Product V in diets. Finally, 2 pairwise comparison contrasts were used to evaluate the effects of 1) adding SMB to DON-contaminated diets and 2) DON-contaminated diets with SMB versus uncontaminated diets with no detoxifying agents present. Differences among contrasts evaluated for the growth experiment were considered significant at $P \leq 0.05$ and marginally significant if $P>0.05$ and $P \leq 0.10$.

The urinary balance experiment was analyzed as a randomized complete block design with individual pig as the experimental unit. Data from the 2 replicates were combined and analyzed for replicate $\times$ treatment interactions. Due to lack of a significant interaction, replicate $\times$ treatment interaction term was removed from the model with replicate and block within replicate included as random effects in the final model. Differences among treatments in the urinary balance experiment were determined using pairwise comparisons protected with an overall treatment effect of $P<$ 0.10 and were considered significant at $P \leq 0.05$.

\section{RESULTS AND DISCUSSION}

Mycotoxin analyses of the high-DON and low-DON wheat at LABOCEA generally matched initial analyses from NDSU, indicating minimal co-contamination with other mycotoxins (Table 2). However, the ground corn used in all diets contained a low level of DON 
Table 2. Mycotoxin analysis of basal ingredients and experimental diets (as-fed basis) ${ }^{1,2}$

\begin{tabular}{|c|c|c|c|c|c|c|c|c|}
\hline \multirow[b]{2}{*}{ Item } & \multicolumn{3}{|c|}{ Basal ingredients } & \multicolumn{5}{|c|}{ Experimental diets ${ }^{3}$} \\
\hline & Ground corn & $\begin{array}{l}\text { High DON } \\
\text { HRW wheat }\end{array}$ & $\begin{array}{c}\text { Low DON } \\
\text { HRW wheat }\end{array}$ & $\begin{array}{c}\text { Positive } \\
\text { Control (PC) }\end{array}$ & $\begin{array}{l}\mathrm{PC}+1.0 \% \\
\text { Product } \mathrm{V}^{5}\end{array}$ & $\begin{array}{c}\text { Negative } \\
\text { Control (NC) }\end{array}$ & $\begin{array}{l}\mathrm{NC}+1.0 \% \\
\text { Product V }\end{array}$ & $\begin{array}{l}\mathrm{NC}+1.0 \% \\
\mathrm{SMB}^{6}\end{array}$ \\
\hline \multicolumn{9}{|l|}{$\overline{\text { Mycotoxin, } \mathrm{mg} / \mathrm{kg}}$} \\
\hline Deoxynivalenol (DON) & 0.57 & 5.70 & 0.05 & 0.04 & 0.06 & 4.10 & 4.23 & 0.35 \\
\hline De-epoxy-DON & - & 0.02 & - & - & - & 0.02 & 0.02 & - \\
\hline 15-Acetyl DON & 0.05 & 0.17 & - & - & - & 0.11 & 0.13 & 0.04 \\
\hline 3-Acetyl DON & 0.01 & 0.06 & - & - & - & 0.03 & 0.03 & - \\
\hline Zearalenone & 0.10 & 0.02 & - & - & - & 0.01 & 0.03 & 0.03 \\
\hline Fumonisin $\mathrm{B}_{1}$ & 8.01 & 0.27 & 0.38 & 0.93 & 0.59 & 0.63 & 0.70 & 0.67 \\
\hline Fumonisin $\mathrm{B}_{2}$ & 1.05 & 0.09 & 0.13 & 0.28 & 0.15 & 0.15 & 0.17 & 0.20 \\
\hline Fumonisin $\mathrm{B}_{3}$ & 0.66 & 0.03 & 0.05 & 0.31 & 0.16 & 0.23 & 0.20 & 0.18 \\
\hline Monoliformine & 0.26 & - & - & - & - & - & - & - \\
\hline Ergot alkaloids ${ }^{7}$ & - & 0.20 & - & - & - & 0.16 & 0.15 & 0.13 \\
\hline \multicolumn{9}{|c|}{$\begin{array}{l}{ }^{2} \text { Basal ingredient and experimental diet samples were sent to LABOCEA in Ploufragan, France for a } 40 \text {-component toxin screen. Samples were analyzed } \\
\text { using liquid chromatography-tandem mass spectrometry with a practical quantitation limit of } 0.01 \mathrm{mg} / \mathrm{kg} \text {. }\end{array}$} \\
\hline \multicolumn{9}{|c|}{${ }^{3}$ Positive control diets formulated to contain $<0.5 \mathrm{mg} / \mathrm{kg}$ DON and all remaining diets formulated to contain $4.0 \mathrm{mg} / \mathrm{kg}$ DON. All diets were pelleted at } \\
\hline $\begin{array}{l}{ }^{4} \text { Hard red winter (HR } \\
{ }^{5} \text { A proprietary blend } \\
{ }^{6} \text { Sodium metabisulfite }\end{array}$ & $\begin{array}{l}\text { V) wheat analyz } \\
\text { absorbent clay } \\
\left(\mathrm{Na}_{2} \mathrm{~S}_{2} \mathrm{O}_{5} \text {; Sam }\right.\end{array}$ & $\begin{array}{l}\text { ed for deoxyni } \\
\mathrm{s} \text { and preservat } \\
\text { irian Chemical }\end{array}$ & $\begin{array}{l}\text { lenol (DON) } \\
\text { es (Nutriquest } \\
\text { Campbell, CA }\end{array}$ & $\begin{array}{l}\text { LC, Mason Cit } \\
\text { ncentration (6.0 }\end{array}$ & $\begin{array}{l}\mathrm{ng} / \mathrm{kg} \text { ) prior } \mathrm{t} \\
\text { IA). }\end{array}$ & diet formulatio & & \\
\hline
\end{tabular}

$(0.57 \mathrm{mg} / \mathrm{kg})$ and a high level of fumonisin B1 (FUM; $8.01 \mathrm{mg} / \mathrm{kg}$ ), which is above cautionary levels for swine. Interactive effects between DON and FUM are well-documented (Grenier et al., 2011; Bracarense et al., 2012) and cannot be ruled out completely, but the low inclusion rate $(4 \%)$ of FUM-contaminated corn in all experimental diets makes the impact of any interactive effects likely minimal on experimental outcomes. The analyzed concentration of DON in final diets in general matched anticipated levels, with the $\mathrm{NC}+\mathrm{SMB}$ diet being the only exception $(0.35 \mathrm{mg} / \mathrm{kg})$. To reiterate, all $3 \mathrm{NC}$ diets were initially prepared as a single, large batch to ensure consistent DON levels. That large batch was then split, and the appropriate detoxifying agent or sand was incorporated prior to pelleting. The decrease in analyzed DON is likely attributed to the formation of 5-fold greater $(P<0.01)$ ratio of DON-sulfonate present in the $\mathrm{NC}+\mathrm{SMB}$ diet compared to the $\mathrm{NC}$ alone. Deoxynivalenol-sulfonate is a nontoxic product formed by the reaction between SMB and DON which is amplified by hydrothermal environmental conditions (Dänicke et al., 2005), such as those present during pelleting in the present study. The presence of low levels of other toxins in experimental diets is most likely inconsequential, as concentrations were well below cautionary limits for growing swine (Thaler and Reese, 2010). Nutrient analyses for CP, Ca, P, and ash content were consistent across experimental diets (Table 3). The addition of $1.0 \%$ Product $\mathrm{V}$ increased $\mathrm{Fe}$ and $\mathrm{Mn}$ levels in the diet by approximately 15 and $60 \%$, respectively. Furthermore, the addition of $1.0 \% \mathrm{SMB}$ increased dietary $\mathrm{S}$ and $\mathrm{Na}$ concentrations approximately 2-fold versus other treatments.

\section{Growth Experiment}

From d 0 to 7, a 2-way interaction for ADFI was detected where adding Product V decreased ADG and ADFI $(P<0.05)$ by a greater magnitude in DONcontaminated diets than in DON-free diets (Table 4). When compared to PC diets, the presence of DON in diets decreased ADG by $52 \%(P<0.001)$, driven by $24 \%$ lower ADFI $(P<0.001)$ and $56 \%$ poorer feed efficiency $(P<0.01)$. However, the addition of SMB to the NC diet markedly improved ADG $(P<0.001)$ and tended to improve ADFI $(P<0.10)$ versus the $\mathrm{NC}$ alone. Nevertheless, from $\mathrm{d} 0$ to 7 , the $\mathrm{NC}+\mathrm{SMB}$ diet tended to decrease ADFI $(P<0.10)$ versus pigs fed the PC.

From $\mathrm{d} 7$ to 14 , no $\mathrm{DON} \times$ Product $\mathrm{V}$ interactions were present. While the previously observed worsening of feed efficiency for NC-fed pigs was not observed, pigs fed NC diets had reduced ADFI $(P<0.01)$ and decreased ADG $(P<0.01)$ relative to pigs fed the PC. Adding Product $\mathrm{V}$ to diets had no effect on ADG, ADFI, or feed efficiency, but the addition of SMB improved ADG $(P<0.001)$ by $20 \%$ compared to the NC, driven primarily by an improvement $(P<0.001)$ in feed efficiency. Pigs fed the NC + SMB diet also exhibited $11 \%$ greater feed efficiency $(P<0.01)$ than pigs fed $\mathrm{PC}$ diets.

From d 14 to 21, a tendency for a 2-way interaction was detected $(P<0.10)$ for ADG where Product 
Table 3. Chemical analysis of diets, as-fed basis ${ }^{1}$

\begin{tabular}{|c|c|c|c|c|c|}
\hline Item & Positive control (PC) & $\mathrm{PC}+1.0 \%$ Product $\mathrm{V}^{2}$ & Negative control (NC) & $\mathrm{NC}+1.0 \%$ Product $\mathrm{V}$ & $\mathrm{NC}+1.0 \% \mathrm{SMB}^{3}$ \\
\hline$\overline{\mathrm{DM}, \%}$ & 89.59 & 89.23 & 89.55 & 89.71 & 89.16 \\
\hline $\mathrm{CP}, \%$ & 22.5 & 22.4 & 22.0 & 22.4 & 22.2 \\
\hline $\mathrm{Ca}, \%$ & 0.80 & 0.80 & 0.82 & 0.77 & 0.76 \\
\hline $\mathrm{P}, \%$ & 0.54 & 0.51 & 0.55 & 0.57 & 0.58 \\
\hline $\mathrm{S}, \%$ & 0.23 & 0.24 & 0.24 & 0.24 & 0.46 \\
\hline $\mathrm{Na}, \%$ & 0.12 & 0.14 & 0.12 & 0.15 & 0.32 \\
\hline $\mathrm{K}, \%$ & 0.85 & 0.83 & 0.85 & 0.92 & 0.92 \\
\hline $\mathrm{Mg}, \%$ & 0.17 & 0.17 & 0.17 & 0.19 & 0.18 \\
\hline $\mathrm{Zn}, \mathrm{mg} / \mathrm{kg}$ & 106 & 92 & 127 & 107 & 109 \\
\hline $\mathrm{Fe}, \mathrm{mg} / \mathrm{kg}$ & 282 & 320 & 270 & 314 & 233 \\
\hline $\mathrm{Mn}, \mathrm{mg} / \mathrm{kg}$ & 63 & 106 & 65 & 102 & 68 \\
\hline $\mathrm{Cu}, \mathrm{mg} / \mathrm{kg}$ & 20 & 22 & 20 & 18 & 23 \\
\hline Ash, \% & 5.3 & 5.0 & 5.3 & 5.2 & 5.1 \\
\hline
\end{tabular}

${ }^{1}$ Dietary samples were collected post-pelleting and sent for chemical analysis at Ward Laboratories (Kearney, NE).

${ }^{2} \mathrm{~A}$ proprietary blend of absorbent clays and preservatives (Nutriquest LLC, Mason City, IA).

${ }^{3}$ Sodium metabisulfite $\left(\mathrm{Na}_{2} \mathrm{~S}_{2} \mathrm{O}_{5}\right.$; Samirian Chemicals, Campbell, CA).

$\mathrm{V}$ inclusion increased ADG in PC diets, but decreased ADG in NC diets. Average daily gain was decreased $(P<0.001)$ for pigs fed the NC, again driven by reduced ADFI $(P<0.001)$ but also by poorer feed efficiency $(P<0.05)$. Product $\mathrm{V}$ addition tended to worsen feed efficiency $(P<0.10)$, but ADG and ADFI were not affected. Supplementation of SMB in NC diets improved ADG, ADFI, and feed efficiency $(P<$ $0.001)$ vs. NC diets alone by the greatest magnitude during the third week of the experiment. Pigs fed the $\mathrm{NC}+\mathrm{SMB}$ also had increased ADG $(P<0.05)$ compared to pigs fed the $\mathrm{PC}$, driven by an $11 \%$ improvement in $\mathrm{G}: \mathrm{F}(P<0.01)$.

Overall, a 2-way interaction was observed for ADG and final BW where Product V supplementation decreased ADG and final BW $(P<0.05)$ and tended to worsen ADFI $(P<0.10)$ in NC diets but did not affect performance in PC diets. Feeding $4 \mathrm{mg} / \mathrm{kg}$ DON in NC diets decreased ADG $(24 \% ; P<0.001)$ and final BW $(P<0.001)$ over the experimental period, reducing ADFI $(P<0.001)$ by $16 \%$ and worsening feed efficiency $(P<0.001)$ by $10 \%$. Supplementing $1.0 \%$ SMB in the NC diet improved ADG, ADFI, and G:F $(P<0.01)$ over NC alone by $35 \%, 10 \%$, and $19 \%$, respectively, resulting in an improvement $(P<0.001)$ in final BW. Unexpectedly, ADG and final BW of pigs fed the NC + SMB diet surpassed even pigs fed the uncontaminated PC diet $(P<0.05)$, primarily driven by an $11 \%$ improvement in feed efficiency $(P<0.001)$.

These results further demonstrate the extent to which high-DON diets can negatively impact nursery pig growth performance. The present data agree with Etienne and Waché (2008), who cited a 4.6\% decrease in ADFI for every $1 \mathrm{mg} / \mathrm{kg}$ of DON in the diet, and Frobose et al. (2015), who described the feed intake suppression pattern as being the most marked during the initial exposure period and lessening over time. The anorexic effects of DON are most frequently attributed to changes in the metabolism and concentration of brain neurotransmitters such as serotonin in cerebrospinal fluid (Prelusky and Trenholm, 1993; Prelusky, 1994), causing delayed gastric emptying and decreasing small-intestinal motility (Rotter et al., 1996). Moreover, pigs develop conditioned taste aversion to DON-contaminated feedstuffs (Ossenkopp et al., 1994), which is consistent with observations of feed refusal and general anxiety in pigs fed DON (Bergsjo et al., 1993; Dänicke et al., 2004a). These effects are more severe in pigs than other species as DON is more rapidly absorbed and distributed to target tissues, and DON clearance from cerebrospinal fluid is slowed (Prelusky et al., 1990).

Previous reports of the impact of DON on feed efficiency have been more variable (Rotter et al., 1996). Long-term exposure to DON-contaminated feed is known to worsen feed efficiency in grow-finish swine (Bergsjo et al., 1993; Dänicke et al., 2004b; Patience et al., 2014), but in a series of 4 nursery pig experiments, Frobose et al. (2015) consistently observed depressed feed efficiency only during the initial 3 to $7 \mathrm{~d}$ of DON-contaminated diet consumption, consistent with the reduction in G:F observed only during $\mathrm{d} 0$ to 7 in the present growth study. This transitory depression in G:F may be partly attributed to wasted feed from pigs sorting due to taste aversion. Additionally, DON reduces villus height (Bracarense et al., 2012), limiting nutrient absorption, and compromises intestinal barrier function (Van De Walle et al., 2010; Pinton et al., 2012), which may increase maintenance requirements. After this initial decrease, the feed efficiency of pigs fed DON-contaminated diets was generally similar to those fed the PC diet. 
Table 4. Effects of potential detoxifying agents on growth performance of nursery pigs fed deoxynivalenol (DON)-contaminated wheat ${ }^{1}$

\begin{tabular}{|c|c|c|c|c|c|c|c|c|c|c|c|}
\hline \multirow{2}{*}{$\begin{array}{l}\text { Item } \\
\begin{array}{l}\text { Detoxifying } \\
\text { agent: }\end{array}\end{array}$} & \multicolumn{2}{|c|}{$\begin{array}{l}\text { Positive control } \\
\text { (PC })^{2}\end{array}$} & \multicolumn{3}{|c|}{$\begin{array}{c}\text { Negative control } \\
(\mathrm{NC} ; 4.0 \mathrm{mg} / \mathrm{kg} \mathrm{DON})^{2}\end{array}$} & \multirow[b]{2}{*}{ SEM } & \multicolumn{5}{|c|}{$\begin{array}{l}\text { Probability, } \\
\qquad P<3\end{array}$} \\
\hline & None & $\begin{array}{c}1.0 \% \text { Product } \\
\mathrm{V}^{4}\end{array}$ & None & $\begin{array}{c}1.0 \% \text { Product } \\
\text { V }\end{array}$ & $\begin{array}{c}1.0 \% \\
\mathrm{SMB}^{5}\end{array}$ & & $\begin{array}{c}\text { DON } \times \text { Product } \\
\text { V }\end{array}$ & DON & $\begin{array}{c}\text { Product } \\
\text { V }\end{array}$ & $\begin{array}{l}\text { SMB vs. } \\
\text { PC }\end{array}$ & $\begin{array}{l}\text { SMB vs. } \\
\text { NC }\end{array}$ \\
\hline \multicolumn{12}{|l|}{$\mathrm{d} 0$ to 7} \\
\hline ADG, $g$ & 380 & 375 & 233 & 151 & 403 & 17.2 & 0.024 & 0.001 & 0.012 & 0.324 & 0.001 \\
\hline ADFI, g & 644 & 643 & 535 & 439 & 588 & 20.5 & 0.022 & 0.001 & 0.019 & 0.054 & 0.055 \\
\hline G:F & 0.590 & 0.583 & 0.440 & 0.335 & 0.686 & 0.029 & 0.081 & 0.001 & 0.045 & 0.020 & 0.001 \\
\hline \multicolumn{12}{|l|}{ d 7 to 14} \\
\hline ADG, $g$ & 534 & 526 & 483 & 454 & 578 & 19.7 & 0.596 & 0.003 & 0.326 & 0.119 & 0.001 \\
\hline ADFI, g & 832 & 837 & 762 & 706 & 814 & 32.0 & 0.320 & 0.003 & 0.414 & 0.696 & 0.221 \\
\hline G:F & 0.648 & 0.628 & 0.633 & 0.646 & 0.710 & 0.015 & 0.271 & 0.913 & 0.813 & 0.006 & 0.001 \\
\hline \multicolumn{12}{|l|}{ d 14 to 21} \\
\hline ADG, $g$ & 582 & 632 & 500 & 484 & 647 & 19.9 & 0.091 & 0.001 & 0.364 & 0.023 & 0.001 \\
\hline ADFI, g & 921 & 936 & 812 & 772 & 912 & 19.5 & 0.144 & 0.001 & 0.511 & 0.738 & 0.001 \\
\hline $\mathrm{G}: \mathrm{F}$ & 0.632 & 0.674 & 0.616 & 0.627 & 0.710 & 0.016 & 0.309 & 0.047 & 0.091 & 0.001 & 0.001 \\
\hline \multicolumn{12}{|l|}{ d 0 to 21} \\
\hline ADG, $\mathrm{g}$ & 498 & 510 & 404 & 363 & 543 & 13.2 & 0.045 & 0.001 & 0.257 & 0.020 & 0.001 \\
\hline ADFI, g & 798 & 805 & 702 & 639 & 772 & 18.3 & 0.056 & 0.001 & 0.113 & 0.291 & 0.007 \\
\hline G:F & 0.625 & 0.634 & 0.576 & 0.567 & 0.704 & 0.011 & 0.429 & 0.001 & 0.987 & 0.001 & 0.001 \\
\hline \multicolumn{12}{|l|}{ Pig BW, kg } \\
\hline $\mathrm{d} 0$ & 13.4 & 13.4 & 13.4 & 13.4 & 13.4 & 0.14 & 0.999 & 0.966 & 0.968 & 0.999 & 0.976 \\
\hline $\mathrm{d} 7$ & 16.1 & 16.1 & 15.1 & 14.5 & 16.3 & 0.15 & 0.066 & 0.001 & 0.043 & 0.429 & 0.001 \\
\hline d 14 & 19.8 & 20.2 & 18.6 & 17.7 & 20.3 & 0.27 & 0.020 & 0.001 & 0.256 & 0.213 & 0.001 \\
\hline $\mathrm{d} 21$ & 23.9 & 24.2 & 22.1 & 21.1 & 24.8 & 0.30 & 0.022 & 0.001 & 0.237 & 0.027 & 0.001 \\
\hline
\end{tabular}

${ }^{1} \mathrm{~A}$ total of 238 barrows and gilts (PIC $327 \times 1050$; initially $13.4 \pm 1.8 \mathrm{~kg} \mathrm{BW}$ and $42 \mathrm{~d}$ of age) were used in a $21 \mathrm{~d}$ experiment with 6 or 7 replicate pens per treatment and 7 pigs per pen. All diets were fed in pelleted form.

${ }^{2}$ Positive control (PC) and negative control (NC) diets formulated to contain $<0.5 \mathrm{mg} / \mathrm{kg}$ and $4.0 \mathrm{mg} / \mathrm{kg} \mathrm{DON}$, respectively.

${ }^{3}$ Each contrast compared the following treatments: 1 ) "DON $\times$ Product V" evaluated the 2-way interaction between DON and adding $1.0 \%$ Product V; 2) "DON" compared PC to NC, excluding only the sodium metabisulfite (SMB) treatment; 3 ) "Product V" compared diets with Product V (2 and 4) to diets without (Diets 1 and 3); and 4) "SMB vs. PC" and "SMB vs. NC" compared the NC diet with 1.0\% SMB to pigs fed the NC or PC diets without detoxifying agents, respectively.

${ }^{4} \mathrm{~A}$ proprietary blend of absorbent clays and preservatives (Nutriquest LLC, Mason City, IA).

${ }^{5}$ Sodium metabisulfite $\left(\mathrm{Na}_{2} \mathrm{~S}_{2} \mathrm{O}_{5}\right.$; Samirian Chemicals, Campbell, CA).

In the present study, the addition of Product $\mathrm{V}$ at $1.0 \%$ in DON-contaminated diets did not alleviate DON's negative effects on nursery pig growth. While Product V did not affect growth when added to the PC diet, when Product V was added to high-DON diets, ADG was suppressed by an additional $11 \%$, mainly driven by $9 \%$ lower ADFI. Although the negative $\mathrm{DON} \times$ Product $\mathrm{V}$ interaction was unexpected, some adsorbing agents have been reported to be nonselective in that they may affect the utilization of essential nutrients, such as vitamins and minerals (Burel et al., 2009). In fact, a review of 23 pig experiments evaluating potential DON-detoxifying agents revealed that the additives tested were twice as likely to worsen rather than benefit pig ADG (Döll and Dänicke, 2003). These observations highlight the importance of using complete factorial designs in studies evaluating mycotoxin detoxifying agents to account for nonspecific effects of the feed additive tested. It may also be im- portant to consider that while inexpensive adsorbing agents are regularly incorporated into swine diets as a prophylactic measure against other mycotoxins, such as aflatoxins, DON is actually the most prevalent mycotoxin in North American cereal grains (Rodrigues and Naehrer, 2012). The data herein and the review by Döll and Dänicke (2003) indicate that the inclusion of these additives may be just as likely to worsen pig growth rather than improve growth if in fact DON is the primary mycotoxin present in diets.

On the contrary, inactivation of DON using SMB appears promising. Pelleting NC diets with $1.0 \% \mathrm{SMB}$ restored the DON-associated reduction in ADFI, which agrees with previous research (Frobose et al., 2011) and is most likely associated with the greater than 10-fold reduction in analyzed DON levels due to conversion to DON-sulfonate. However, pelleting $\mathrm{NC}$ diets with SMB also resulted in consistent improvement in feed efficiency throughout the duration of the experiment ver- 
Table 5. Urinary excretion of deoxynivalenol (DON), DON-sulfonate, and the metabolite de-epoxy-DON (DOM1) in pigs fed DON-contaminated diets with or without potential detoxifying agents ${ }^{1}$

\begin{tabular}{|c|c|c|c|c|}
\hline \multirow{2}{*}{$\frac{\text { Item }}{\text { Detoxifying agent: }}$} & \multicolumn{3}{|c|}{ Negative control $(4.0 \mathrm{mg} / \mathrm{kg}$ DON$)$} & \multirow[t]{2}{*}{ SEM } \\
\hline & None & $1.0 \%$ Product $\mathrm{V}^{2}$ & $1.0 \% \mathrm{SMB}^{3}$ & \\
\hline Analyzed dietary DON, mg $/ \mathrm{kg}^{4}$ & 4.28 & 4.63 & 0.22 & \\
\hline DON-sulfonate relative to $\mathrm{NC}^{5}$ & 1.00 & 0.73 & 5.67 & 1.318 \\
\hline ADFI, kg & 1.46 & 1.46 & 1.47 & 0.045 \\
\hline Urine output, L & $20.5^{\mathrm{ab}}$ & $18.2^{\mathrm{a}}$ & $26.3^{\mathrm{b}}$ & 2.16 \\
\hline DON consumption, $\mathrm{mg} / \mathrm{d}$ & $6.21^{\mathrm{b}}$ & $6.79^{\mathrm{b}}$ & $0.32^{\mathrm{a}}$ & 0.223 \\
\hline \multicolumn{5}{|l|}{ Excretion in urine, mg/d } \\
\hline DON & $3.65^{\mathrm{b}}$ & $3.29^{\mathrm{b}}$ & $0.52^{\mathrm{a}}$ & 0.164 \\
\hline DOM-1 & $0.54^{\mathrm{b}}$ & $0.39^{\mathrm{ab}}$ & $0.18^{\mathrm{a}}$ & 0.103 \\
\hline \multicolumn{5}{|l|}{ Excretion in urine [\% of DON intake] } \\
\hline DON & $58.7^{\mathrm{a}}$ & $48.2^{\mathrm{a}}$ & $164.4^{\mathrm{b}}$ & 6.80 \\
\hline DOM-1 & $0.24^{\mathrm{a}}$ & $0.21^{\mathrm{a}}$ & $0.87^{\mathrm{b}}$ & 0.037 \\
\hline
\end{tabular}

${ }^{1}$ A total of 24 barrows (PIC $327 \times 1,050 ; 42.5 \pm 1.7 \mathrm{~kg}$ and $51.8 \pm 3.5 \mathrm{~kg}$ at the onset of the collection period for replicate 1 and 2, respectively) over 2 replicate groups $(n=12)$ were used in a $17 \mathrm{~d}$ experiment with 8 pigs per treatment. The collection period (d 11 to 17$)$ is shown above. All diets were fed in pelleted form.

${ }^{2} \mathrm{~A}$ proprietary blend of absorbent clays and preservatives (Nutriquest LLC, Mason City, IA).

${ }^{3}$ Sodium metabisulfite $\left(\mathrm{Na}_{2} \mathrm{~S}_{2} \mathrm{O}_{5}\right.$; Samirian Chemicals, Campbell, $\left.\mathrm{CA}\right)$.

${ }^{4}$ Analyzed at LABOCEA (Ploufragan, France) using liquid chromatography-tandem mass spectrometry with a practical quantitation limit of $0.01 \mathrm{mg} / \mathrm{kg}$. The average of 2 replicate groups is reported.

${ }^{5}$ Analyzed at the Kansas State University Lipidomics Laboratory using liquid chromatography-tandem mass spectrometry. Peak areas of DON-sulfonate in the NC $+\mathrm{SMB}$ diet were compared to the peak areas of DON-sulfonate in the NC diet and presented as a ratio.

a,b Means without a common superscript differ, $P<0.05$.

sus not only the NC (18\%) but also compared to pigs fed the uncontaminated PC diet (11\%), suggesting that part of the SMB benefit may be independent of DONcontamination. While the biological mechanism remains unclear, the presently observed feed efficiency benefit was also reported by Dänicke et al. (2005), who also fed DON-contaminated wheat hydrothermally treated with SMB to growing pigs. Furthermore, Burnham et al. (1994) realized G:F benefits when a similar compound, sodium sulfite, was added at $1.0 \%$ to traditional or extruded soybean meal and fed to pigs. These reports imply that hydrothermal treatment with sulfites may improve nutrient availability for the animal. Unfortunately, due to lack of additional pen space, a sixth treatment using the PC diet plus SMB could not be added to the present study. These data underscore the need to further investigate SMB as a means to enhance pig growth, regardless of the mycotoxin status of the diet.

The release of sulfur dioxide when pelleting diets containing SMB is a concern for feed mill employees. Acute sulfur dioxide exposure causes irritation to the eyes and respiratory tract (Nair and Elmore, 2003) and therefore may require the use of protective equipment. Despite being classified as "generally recognized as safe" by the U.S. Food and Drug Administration, SMB and other sulfites are known to degrade thiamine (Til et al., 1972) and are therefore excluded from use in foods recognized as significant sources of the vitamin (Nair and Elmore, 2003). Thiamine deficiency requires time to develop in pigs (up to $35 \mathrm{~d}$; Gibson et al., 1987), but is characterized by neurological symptoms and can be fatal if left untreated (Hough et al., 2014). Accordingly, unless supplemental thiamine can be delivered externally (e.g., water or injectable) when feeding SMB-treated feed, opportunities beyond short-term SMB use may be limited. Given these concerns, additional research is necessary to determine the minimum SMB level necessary and acceptable feeding duration to minimize feed processing and thiamine deficiency concerns.

\section{Urinary Balance Experiment}

The experimental diets used in the urinary balance experiment were sampled daily within each replicate and a subsample of each was sent for mycotoxin analysis at LABOCEA (Table 5). Analyzed DON concentrations were generally similar to those used in the growth study. Daily feed intake was set by the amount of feed consumed daily by $\mathrm{NC}$ fed pigs during the $10 \mathrm{~d}$ adaptation period and no differences in feed disappearance were observed between treatments during the collection period. Pigs fed the $\mathrm{NC}+\mathrm{SMB}$ diet had the greatest urine output during the collection period, being significantly greater $(P<0.05)$ than pigs fed $\mathrm{NC}+$ Product $\mathrm{V}$, with NC pigs intermediate. The additional urinary excretion is likely attributed to increased water intake due to the elevated dietary $\mathrm{Na}$ when $1.0 \% \mathrm{SMB}$ was incorporated into the diet (Patience and Zijlstra, 2001). 
As calculated from analyzed DON levels, pigs fed $\mathrm{NC}$ and $\mathrm{NC}+$ Product $\mathrm{V}$ treatments consumed a greater amount of DON per d $(P<0.001)$ than pigs fed the $\mathrm{NC}+$ SMB diet, since DON conversion to DON-sulfonate occurred during feed manufacturing when SMB was added prior to pelleting. The DON-sulfonate analysis confirmed that DON to DON-sulfonate conversion was over 5 -fold greater $(P<0.01)$ when $1.0 \%$ SMB was added to $\mathrm{NC}$ diets prior to pelleting versus the $\mathrm{NC}$ alone and $\mathrm{NC}+$ Product V. Although DON-sulfonate is known to lack the emetic activity of DON (Young et al., 1987), interestingly, the addition of SMB to NC diets did not reduce the incidence of vomiting. In fact, $\mathrm{NC}+\mathrm{SMB}$ pigs vomited on 10 occasions as compared to 7 and 3 for the $\mathrm{NC}$ and $\mathrm{NC}+$ Product $\mathrm{V}$ treatments, respectively (data not shown). Still, the daily DON urinary excretion was reduced $(P<0.001)$ for $\mathrm{NC}+\mathrm{SMB}$ fed pigs versus the $\mathrm{NC}$ and $\mathrm{NC}+$ Product $\mathrm{V}$, and the excretion of the primary metabolite DOM-1 was also less $(P<0.05)$ in the NC + SMB pigs. However, when expressed as a percentage of daily DON intake, pigs fed the $\mathrm{NC}+\mathrm{SMB}$ diet excreted more DON than they consumed $(164 \%)$, which was greater $(P<0.001)$ than pigs fed NC $(59 \%)$ or the NC + Product V (48\%) diet.

For pigs fed the $\mathrm{NC}+\mathrm{SMB}$ treatment, DON recovery greater than $100 \%$ appears to indicate that some of the DON-sulfonate was degraded to the parent DON. Recent work by Schwartz et al. (2013) revealed that 3 structurally unique forms of DON-sulfonate can be formed by the reaction of DON with sulfites, dependent on the sulfiting agent and processing conditions present. While DON-sulfonate-1 and DON-sulfonate-2 are stable across a broad $\mathrm{pH}$ range, DON-sulfonate- 3 can decompose to DON at alkaline $\mathrm{pH}$, such as those in the proximal small intestine. Schwartz-Zimmerman et al. (2014) compared sulfiting agents in a follow-up study and found the predominant form produced by the reaction between DON and SMB to be DON-sulfonate-3. If the sulfonate formation profile was similar in the present study, this would explain the degradation of a portion of DON-sulfonate-3 back into DON, which would then be detected as additional DON in the urine. Since the gross DON urine recovery remained only $15 \%$ of the DON ingested by pigs fed the $\mathrm{NC}$ or $\mathrm{NC}+$ Product $\mathrm{V}$ diets, the physiological impact from the degradation of DON-sulfonate back to DON in the digestive tract was likely minimal in the present study. Nevertheless, this degradation pattern is important to consider for future research to potentially enhance the efficacy of the reaction with $\mathrm{SMB}$ and lower the dietary concentration of SMB needed to alleviate the effects of DON.

The recovery of DON from pigs fed the $\mathrm{NC}$ and $\mathrm{NC}+$ Product $\mathrm{V}$ matches urinary DON recovery rates in previous work. For example, the urinary recovery of ingested DON was $50 \%$ to $63 \%$ in Friend et al. (1986) and $42 \%$ to $72 \%$ in Dänicke et al. (2004a). Since urine is the main DON absorption and excretion route, if Product V was able to decrease the uptake of DON, urinary DON excretion would also be decreased. However, in the present study, DON recovery was similar between pigs fed $\mathrm{NC}$ or $\mathrm{NC}+$ Product $\mathrm{V}$ diets, and the lack of a Product V response in urinary metabolism is congruent with the lack of the growth benefit to Product $\mathrm{V}$. Since pigs have limited ability to de-epoxidate DON other than via microbial fermentation in the hindgut, recovery of urinary DOM- 1 was minimal $(0.2 \%$ to $0.9 \%$ of DON intake) but consistent with previous work ( $0 \%$ to $1.1 \%$; Dänicke et al., 2004a).

In summary, feeding diets contaminated with $4 \mathrm{mg} /$ $\mathrm{kg}$ DON to nursery pigs reduces nursery pig growth, most severely during the initial exposure period and primarily via feed intake suppression. The addition of Product V did not alleviate the DON-associated effects on pig growth nor did it reduce DON absorption and urinary excretion compared to pigs fed DON-contaminated diets alone. However, treating DON-contaminated diets with 1.0\% SMB restored feed intake and improved feed efficiency markedly. Even so, the urinary balance experiment revealed that a portion of the converted DONsulfonate can be degraded back to DON under physiological conditions. While questions remain surrounding processing methods and long-term supplementation effects of SMB, this research demonstrates that pelleting DON-contaminated diets with SMB can alleviate DON effects on growth. Additional research is also needed to evaluate the effect of sodium metabisulfite on feed efficiency in uncontaminated diets.

\section{LITERATURE CITED}

Bergsjo, B., W. Langseth, I. Nafstad, J. H. Jansen, and H. J. S. Larsen. 1993. The effects of naturally deoxynivalenol-contaminated oats on the clinical condition, blood parameters, performance and carcass composition of growing pigs. Vet. Res. Commun. 17:283-294.

Beyer, M., S. Danicke, D. Rohweder, and H.-U. Humpf. 2010. Determination of deoxynivalenol-sulfonate (DONS) in cereals by hydrophilic interaction chromatography coupled to tandem mass spectrometry. Mycotoxin Res. 26:109-117.

Bracarense, A.-P. F. L., J. Lucioli, B. Grenier, G. D. Pacheco, W.D. Moll, G. Schatzmayr, and I. P. Oswald. 2012. Chronic ingestion of deoxynivalenol and fumonisin, alone or in interaction, induces morphological and immunological changes in the intestine of piglets. Br. J. Nutr. 107:1776-1786.

Burel, S. D., M. C. Favrot, J. M. Fremy, C. Massimi, P. Prigent, L. P. Debongnie, and D. Morgavi. 2009. Review of mycotoxindetoxifying agents used as feed additives: Mode of action, efficacy and feed/food safety. EFSA-Q-2009-00839, EFSA J. 8 December 2009. 
Burnham, L. L., J. D. Hancock, I. H. Kim, T. L. Gugle, and R. H. Hines. 1994. Sodium sulfite and extrusion affect the nutritional value of soybean products for nursery pigs. Kansas State Univ. Swine Day Rep. of Prog. Manhattan, KS. p. 63 67.

CAST. 2003. Mycotoxins: Risks in plant, animal, and human systems. Rep. 116. Counc. Agric. Sci. Technol., Ames, IA. p. 133-135.

Dänicke, S. 2002. Fusariums toxins in animal nutrition. Lohmann Inf. 27:29-37.

Dänicke, S., T. Goyarts, H. Valenta, E. Razzazi, and J. Bohm. 2004a. On the effects of deoxynivalenol (DON) in pig feed on growth performance, nutrients utilization and DON metabolism. J. Anim. Feed Sci. 13:539-556.

Dänicke, S., H. Valenta, S. Döll, M. Ganter, and G. Flachowsky. 2004b. On the effectiveness of a detoxifying agent in preventing fusario-toxicosis in fattening pigs. Anim. Feed Sci. Technol. 114:141-157.

Dänicke, S., H. Valenta, M. Gareis, H. W. Lucht, and H. von Reichenbach. 2005. On the effects of a hydrothermal treatment of deoxynivalenol (DON)-contaminated wheat in the presence of sodium metabisulfite $\left(\mathrm{Na}_{2} \mathrm{~S}_{2} \mathrm{O}_{5}\right)$ on DON reduction and piglet performance. Anim. Feed Sci. Technol. 118:93-108.

Danicke, S., T. Goyarts, and H. Valenta. 2007. On the specific and unspecific effects of a polymeric qlucomannan mycotoxin adsorbent on piglets when fed with uncontaminated or with Fusarium toxins contaminated diets. Arch. Anim. Nutr. 61(4):266-275.

Danicke, S., H. Valenta, and S. Kersten. 2012. Humic substances failed to prevent the systemic absorption of deoxynivalenol (DON) and its adverse effects on piglets. Mycotoxin Res. 28:253-260.

Döll, S., and S. Dänicke. 2003. On the efficacy of detoxifying agents in the prevention of fusariotoxicosis- a critical evaluation of the situation. Mycotoxin Res. 19:185-189.

Etienne, M., and Y. Waché. 2008. Biological and physical effects of deoxynivalenol (DON) in the pig. In: I. Oswald and I. Taranu, editors, Mycotoxins in farm animals. Transworld Research Network, Kerala, India. p. 113-130.

Friend, D. W., H. L. Trenholm, J. C. Young, B. K. Thompson, and K. E. Hartin. 1984. Effect of adding potential vomitoxin (deoxynivalenol) detoxicants or a $\mathrm{F}$. graminearum inoculated corn supplement to wheat diets fed to pigs. Can. J. Anim. Sci. 64:733-741.

Friend, D. W., H. L. Trenholm, B. K. Thompson, D. B. Prelusky, and K. E. Hartin. 1986. Effect of deoxynivalenol (DON)contaminated diet fed to growing-finishing pigs on their performance at market weight, nitrogen retention and DON excretion. Can. J. Anim. Sci. 66:1075-1085.

Frobose, H. L., E. D. Fruge, M. D. Tokach, E. L. Hansen, J. M. DeRouchey, S. S. Dritz, R. D. Goodband, and J. L. Nelssen. 2011. Kansas State Univ. Swine Day Rep. of Prog. 1056. Manhattan, KS. p. 105-113.

Frobose, H. L., E. D. Fruge, M. D. Tokach, E. L. Hansen, J. M. DeRouchey, S. S. Dritz, R. D. Goodband, and J. L. Nelssen. 2015. The effects of deoxynivalenol-contaminated corn dried distillers grains with solubles in nursery pig diets and potential for mitigation by commercially available feed additives. J. Anim. Sci. 93:1074-1088.

Gibson, D. M., J. J. Kennelly, and F. X. Aherne. 1987. The performance and thiamin status of pigs fed sulfur dioxide treated high-moisture barley. Can. J. Anim. Sci. 67:841-854.
Grenier, B., A.-P. Loureiro-Bracarense, J. Lucioli, G. D. Pacheco, A.-M. Cossalter, W.-D. Moll, G. Schatzmayr, and I. P. Oswald. 2011. Individual and combined effects of subclinical doses of deoxynivalenol and fumonisins in piglets. Mol. Nutr. Food Res. 55:761-771.

Hough, S. D., S. H. Jennings, and G. W. Almond. 2014. Thiamineresponsive neurological disorder of swine. J. Swine Health Prod. 23(3):143-151.

Nair, B., and A. R. Elmore. 2003. Final report on the safety assessment of sodium sulfite, potassium sulfite, ammonium sulfite, sodium bisulfite, ammonium bisulfite, sodium metabisulfite and potassium metabisulfite. Int. J. Toxicol. 22(Suppl. 2):6388.

NRC. 2012. Nutrient Requirements of Swine., 11th rev. ed. Natl. Acad. Press, Washington, DC.

Ossenkopp, K.-P., M. Hirst, and W. A. Rapley. 1994. Deoxynivalenol (vomitoxin)-induced conditioned taste aversion in rats are mediated by the chemosensitive area postrema. Pharmacol. Biochem. Behav. 47:363-367.

Patience, J. F., and R. T. Zijlstra. 2001. Sodium, potassium, chloride, magnesium, and sulfur in swine nutrition. In: A. J. Lewis and L. L. Southern, editors, Swine nutrition. 2nd ed. CRC Press, Boca Raton, FL. p. 222-224.

Patience, J. F., A. J. Myers, S. Ensley, B. M. Jacobs, and D. Madson. 2014. Evaluation of two mycotoxin mitigation strategies in grow-finish swine diets containing cord dried distillers grains with solubles naturally contaminated with deoxynivalenol. J. Anim. Sci. 92:620-626.

Paulick, M., I. Rempe, S. Kersten, D. Schatzmayr, H. E. SchwartzZimmerman, and S. Danicke. 2015. Effects of increasing concentrations of sodium sulfite on deoxynivalenol and deoxynivalenol sulfonate concentrations of maize kernels and maize meal preserved at various moisture content. Toxins (Basel) 7:791-811.

Pestka, J. J., H.-R. Zhou, Y. Moon, and Y. J. Chung. 2004. Cellular and molecular mechanisms for immune modulation by deoxynivalenol and other trichothecenes: Unraveling a paradox. Toxicol. Lett. 153:61-73.

Pinton, P., D. Tsybulskyy, J. Lucioli, J. Laffitte, P. Callu, F. Lyazhri, F. Grosjean, A. P. Bracarense, M. Kolf-Clauw, and I. P. Oswald. 2012. Toxicity of deoxynivalenol and its acetylated derivatives on the intestine: Differential effects on morphology, barrier function, tight junction proteins and mitogenactivated protein kinases. Toxicol. Sci. 130(1):180-190.

Prelusky, D. B., K. E. Hartin, and H. L. Trenholm. 1990. Distribution of deoxynivalenol in cerebral spinal fluid following administration to swine and sheep. J. Environ. Sci. Health B 25:395-413.

Prelusky, D. B., and H. L. Trenholm. 1993. The efficacy of various classes of anti-emetics in preventing deoxynivalenol-induced vomiting in swine. Nat. Toxins 1:296-302.

Prelusky, D. B. 1994. The effect of deoxynivalenol on serotoninergic neurotransmitter levels in pig blood. J. Environ. Sci. Health B 29:1203-1218.

Rodrigues, I., and K. Naehrer. 2012. A three-year survey on the worldwide occurrence of mycotoxins in feedstuffs and feed. Toxins (Basel) 4:663-675.

Rotter, B. A., D. B. Prelusky, and J. J. Pestka. 1996. Toxicology of deoxynivalenol (vomitoxin). J. Toxicol. Environ. Health 48:1-34 
Schwartz, H. E., C. Hametner, V. Slavik, O. Greitbauer, G. Bichl, E. Kunz-Vekiru, D. Schatzmayr, and F. Berthiller. 2013. Characterization of three deoxynivalenol sulfonates formed by reaction of deoxynivalenol with sulfur reagents. J. Agric. Food Chem. 61:8941-8948.

Schwartz-Zimmerman, H.E., G. Weisenberger, C. Unbekannt, S. Hessenberger, D. Schatzmayr, and F. Berthiller. 2014. Reaction of (conjugated) deoxynivalenol with sulphur reagents - needed to evaluate the effect of sodium metabisulfite on feed efficiency in uncontaminated diets. World Mycotoxin J. 7:187-197.

Til, H. P., V. J. Feron, A. P. de Groot, and P. van der Wal. 1972. The toxicity of sulphite. II. Short- and long-term feeding studies in pigs. Food Cosmet. Toxicol. 10:463-473.
Thaler, B., and D. E. Reese. 2010. Utilization of weather stressed feedstuffs in swine. In: D. J. Meisinger, editor, National swine nutrition guide. US Pork Cent. Excellence, Ames, IA. p. 207-213.

Van De Walle, J., T. Sergent, N. Piront, O. Toussaint, Y.-J. Schneider, and Y. Larondelle. 2010. Deoxynivalenol affects in vitro intestinal epithelial cell barrier integrity through inhibition of protein synthesis. Toxicol. Appl. Pharmacol. 245:291-298.

Young, J. C., L. M. Subryan, D. Potts, M. E. McLaren, and F. H. Gobran. 1986. Reduction in levels of deoxynivalenol in contaminated wheat by chemical and physical treatment. J. Agric. Food Chem. 34:461-465.

Young, J. C., H. L. Trenholm, D. W. Friend, and D. B. Prelusky. 1987. Detoxification of deoxynivalenol with sodium bisulfite and evaluation of the effects when pure mycotoxin or contaminated corn was treated and given to pigs. J. Agric. Food Chem. 35:259-261. 